\title{
Effect of intravenous ranitidine and omeprazole on intestinal absorption of water, sodium, and macronutrients in patients with intestinal resection
}

\author{
P B Jeppesen, M Staun, L Tjellesen, P B Mortensen
}

\begin{abstract}
Background $-\mathrm{H}_{2}$ receptor blockers and proton pump inhibitors reduce intestinal output in patients with short bowel syndrome.

Aims-To evaluate the effect of intravenous omeprazole and ranitidine on water, electrolyte, macronutrient, and energy absorption in patients with intestinal resection.

Methods-Thirteen patients with a faecal weight above $1.5 \mathrm{~kg} /$ day (range 1.7-5.7 $\mathrm{kg} / \mathrm{day}$ and a median small bowel length of $100 \mathrm{~cm}$ were studied. Omeprazole $40 \mathrm{mg}$ twice daily or ranitidine $150 \mathrm{mg}$ twice daily were administered for five days in a randomised, double blind, crossover design followed by a three day control period with no treatment. Two patients with a segment of colon in continuation were excluded from analysis which, however, had no influence on the results. Results-Omeprazole increased median intestinal wet weight absorption compared with no treatment and ranitidine $(p<0.03)$. The effect of ranitidine was not significant. Four patients with faecal volumes below $2.6 \mathrm{~kg} / \mathrm{day}$ did not respond to omeprazole; in two absorption increased by $0.5-1 \mathrm{~kg} / \mathrm{day}$; and in five absorption increased by 1-2 kg/day. Absorption of sodium, calcium, magnesium, nitrogen, carbohydrate, fat, and total energy was unchanged. Four high responders continued on omeprazole for 12-15 months, but none could be weaned from parenteral nutrition.

Conclusion-Omeprazole increased water absorption in patients with faecal output above $2.50 \mathrm{~kg} / \mathrm{day}$. The effect varied significantly and was greater in patients with a high output, but did not allow parenteral nutrition to be discontinued. Absorption of energy, macronutrients, electrolytes, and divalent cations was not improved. The effect of ranitidine was not significant, possibly because the dose was too low.

(Gut 1998;43:763-769)
\end{abstract}

Keywords: short bowel syndrome; human; diarrhoea; ranitidine; omeprazole

Patients with a short bowel and high intestinal output are at risk of developing malnutrition, and salt and water depletion due to the excessive faecal loss of energy, fluid, and electrolytes. A negative energy, fluid, and electrolyte balance may necessitate prolonged parenteral supplementation, imposing the need for a central venous catheter. A high intestinal output thus has a major impact on the quality of life in these patients, who experience restrictions in social and leisure activities. ${ }^{12}$

The loss of intestinal fluid in patients with high intestinal output most likely reflects the loss of normal daily secretions produced in response to food intake. Increased duodenal volume could flush and dilute nutrients and electrolytes, thereby impairing intraluminal food assimilation and fluid and electrolyte absorption. The transient gastric hypersecretion, which occurs after massive small bowel resection, ${ }^{3}$ may affect the digestive and absorptive processes by inactivating pancreatic enzymes and precipitating bile salts. ${ }^{4-6}$ There are, however, no data to support the hypothesis that gastric acid hypersecretion continues for longer periods in patients with a short bowel. The effects of both oral and intravenous histamine $\mathrm{H}_{2}$ receptor antagonists have been studied in patients with a short bowel, but the effect of proton pump inhibitors has only been studied when given orally. ${ }^{78}$ At present, the effect of $\mathrm{H}_{2}$ receptor antagonists and proton pump inhibitors on nutrient absorption remains unclear, ${ }^{9}$ and the importance of gastric acid secretion on absorption of divalent cations is controversial. ${ }^{10} 11$

This double blind, randomised study evaluated the effect of intravenous omeprazole versus ranitidine, compared with a control period, on the absorption of water, electrolytes, divalent cations, nutrients, and energy in patients with a short bowel.

\section{Material and methods}

PATIENTS

Thirteen patients with a stool weight above $1.50 \mathrm{~kg} /$ day were studied. All patients except one had undergone extensive small bowel resection. Two patients had a remnant colon segment and were excluded from the statistical analysis; they are dealt with separately throughout the study. The reason for the resection in the 11 patients with jejunostomy or ileostomy was Crohn's disease $(n=9)$ or mesenteric vascular disease $(n=2)$. In the two patients with a remnant colon segment it was Crohn's disease and a midgut volvolus. The length of the remaining small intestine from the ligament 
of Treitz was measured peroperatively and obtained from the operative reports in nine of the 11 patients. One patient did not have a small bowel resection and in one patient the length of the resected intestine was $150 \mathrm{~cm}$. The small intestine was measured in both patients with a remnant colon segment. No patient had had stomach or duodenal surgery.

At inclusion, the patients were in a stable phase with no surgical treatment having been performed within the past six months. None of the patients with inflammatory bowel disease had any clinical or biochemical signs of active disease. Five of the 11 patients did not use antidiarrhoeal medications. Two patients took a codeine preparation, two loperamide, one diphenoxylate and atropine, and two a tincture of opium. Neither of the two patients with a remnant colon segment took antidiarrhoeal medications. All patients were closely monitored and were included in our programme for patients on home parenteral nutrition and gut failure at Rigshospitalet, Copenhagen. The physical activity was normal in all patients, but only one had full time employment. The fluid and nutritional balance was in steady state as indicated by stable weight, which remained constant with a margin of $2 \mathrm{~kg}$ during the study period. Dietary consumption generally was unrestricted. Twelve of the 13 patients received parenteral nutrition, which supplied energy and electrolytes from three to seven times per week. Both of the patients with a remnant colon segment received parenteral nutrition. The composition of the nutritional programme had been unchanged for at least three months before inclusion.

STUDY PROTOCOL

Patients were admitted for two study periods of five days each and a subsequent three day control period. During the two five day treatment periods patients were given either omeprazole $40 \mathrm{mg}$ or ranitidine $150 \mathrm{mg}$ intravenously twice daily in a randomised, crossover design. Medication was given at 830 am and pm in a double blinded manner using a double dummy technique. During the three day control period, patients did not receive either omeprazole or ranitidine. The treatment periods were separated by at least one week.

Patients were given identical fixed diets, with a calculated energy ratio of $40: 20: 40 \%$ carbohydrate:protein:fat during the study and control periods. The energy content of the diet was established from a three day, dietary record obtained before admission and adjusted according to an interview with a dietician at the first admission. The diets were prepared in duplicate in our metabolic ward kitchen, and the supply of the various food components was calculated from standard food tables. At the first admission patients were informed that they were allowed an unrestricted intake of salt and beverages. They were instructed to record the intake and furthermore to keep the intake of salt and beverage constant during the following days and periods of admission. To ensure patient compliance we prepared a beverage and salt record, and the patients were told to mark the intake of salt and beverages on a check list. An identically prepared duplicate meal was pooled with the collected duplicate beverages and salt from a 24 hour period and analysed. Any deviations from the fixed diet and beverage programme were recorded and counterbalanced in the analysis and calculations. All medications were kept constant during the study periods. Two patients who had already received ranitidine were instructed not to take this medication seven days before admission. Four patients, one of whom had a remnant colon segment, receiving octreotide $50 \mu \mathrm{g}$ subcutaneously twice a day were instructed to maintain this treatment. Patients continued with their usual weekly parenteral programme and adjustments, if any, were recorded.

During the last four days in the study periods and during the last two days in the control period faeces and urine were collected. The faeces were collected on ice and immediately frozen at $-20^{\circ} \mathrm{C}$ until analysis. Analysis of oral input and faecal output was done on homogenised and freeze dried aliquots of 24 hour pooled samples and the results were presented as median values for each test period. Urine was kept refrigerated and analysed on a daily basis. Body weight was measured every morning after disconnection of parenteral supplements, urination, and emptying of stoma bags (or defecation).

ANALYTICAL METHODS

Sodium and potassium in diet, faeces, and urine were measured by flame photometry (Model 143, Instrumentation Laboratory Inc., Boston, Massachusetts, USA), and calcium and magnesium by atomic absorption spectrophotometry (Model 3100, Perkin Elmer, Connecticut, USA). Dietary and faecal energy content were determined by bomb calorimetry with approximately $1 \mathrm{~g}$ of freeze dried 24 hour samples ignited in an IKA adiabatic calorimeter (Model C 4000 A, IKA-Analysentechnik, Heitersheim, Germany). Absorption was calculated as the difference between ingested and excreted energy.

Dietary and faecal nitrogen was determined by the technique of Kjeldahl. ${ }^{12}$ The dietary and faecal content of total carbohydrate was determined by acid hydrolysis (12 $\mathrm{M} \mathrm{H}_{2} \mathrm{SO}_{4}$ ) and colorimetry at $530 \mathrm{nM}$, as described by Englyst. ${ }^{13}$

Dietary and faecal fatty acids were determined by combined gas-liquid chromatography and mass spectrometry. Internal standards obtained from Merck were C9:0, C13:0, and $\mathrm{C} 17: 0 ; 1 \mathrm{~g}$ of each was dissolved in chloroform to a volume of $100 \mathrm{ml}$. Internal standard solution $(250 \mu \mathrm{l})$ was evaporated under nitrogen in tubes equipped with Teflon lined screw caps. Homogenised faeces or diet $(0.5 \mathrm{~g})$ was applied with $1 \mathrm{ml}$ of $\mathrm{KOH} 33 \%$ and $4 \mathrm{ml}$ of ethanol:amylalcohol (94:4), and the screw caps were tightened. The solution was incubated in a boiling water bath for 30 minutes with periods of shaking every 10 minutes. After saponification ethanol was evaporated under nitrogen. A $1.7 \mathrm{ml}$ aliquot of $6 \mathrm{~mol} / 1 \mathrm{HCl}$ and 
Table 1 Diet and supplemental parenteral support

\begin{tabular}{lllll}
\hline & Control & Ranitidine & Omeprazole & $p$ Value $^{*}$ \\
\hline Diet & & & & \\
Weight (kg/day) & $4.30(3.75-5.18)$ & $4.29(3.44-4.82)$ & $4.41(3.48-4.82)$ & 0.52 \\
Sodium (mmol/day) & $198(173-236)$ & $218(147-285)$ & $179(151-243)$ & 0.85 \\
Potassium (mmol/day) & $87(65-113)$ & $100(65-104)$ & $87(66-101)$ & 0.08 \\
Calcium (mmol/day) & $34(32-39)$ & $34(27-44)$ & $34(31-42)$ & 0.44 \\
Magnesium (mmol/day) & $17(14-22)^{\mathrm{a}}$ & $15(13-19)^{\mathrm{b}}$ & $15(13-18)^{\mathrm{b}}$ & 0.04 \\
Energy (MJ/day) & $10.33(7.97-10.67)$ & $9.36(7.71-11.53)$ & $10.05(8.98-12.06)$ & 0.09 \\
Nitrogen (g/day) & $14.7(12.9-17.6)$ & $14.4(12.2-16.8)$ & $13.7(12.1-15.7)$ & 0.08 \\
Carbohydrate (g/day) & $207.1(162.4-244.3)$ & $223.3(144.0-255.5)$ & $218.1(185.7-270.0)$ & 0.40 \\
Total fatty acids (g/day) & $77.5(54.5-83.5)$ & $74.3(63.0-79.4)$ & $69.0(61.5-79.6)$ & 0.37 \\
Saturated FA (g/day) & $44.1(30.4-48.9)$ & $43.7(36.5-47.5)$ & $39.6(36.1-47.5)$ & 0.37 \\
Unsaturated FA (g/day) & $30.3(22.2-35.8)$ & $31.1(25.9-32.9)$ & $29.5(25.5-32.7)$ & 0.64 \\
Parenteral support & & & & \\
Weight (kg/day) & $1.99(1.50-4.44)$ & $1.99(1.50-3.51)$ & $1.99(1.50-4.51)$ & 0.58 \\
Sodium (mmol/day) & $184(66-345)$ & $187(66-335)$ & $132(66-332)$ & 0.42 \\
Potassium (mmol/day) & $38(23-47)$ & $38(25-50)$ & $38(15-55)$ & 1.00 \\
Calcium (mmol/day) & $4.5(2.9-5.6)$ & $4.5(3.0-6.6)$ & $4.5(2.9-6.6)$ & 0.76 \\
Magnesium (mmol/day) & $5.0(3.1-6.3)$ & $5.0(3.3-7.3)$ & $5.0(3.0-7.3)$ & 0.76 \\
Energy (MJ/day) & $2.91(1.93-3.38)$ & $3.11(1.98-4.82)$ & $3.38(1.83-4.88)$ & 0.14 \\
Nitrogen (g/day) & $6.8(4.2-6.8)$ & $6.8(3.9-8.5)$ & $6.8(2.9-8.5)$ & 0.91 \\
Carbohydrate (g/day) & $137(105-188)$ & $177(108-258)$ & $188(84-262)$ & 0.14 \\
Fatty acids (g/day) & $0.0(0.0-0.0)$ & $0.0(0.0-0.0)$ & $0.0(0.0-0.0)$ & 1.00 \\
\hline
\end{tabular}

Values are median $(25-75 \%)$.

abc Significant difference between study periods, $\mathrm{p}<0.05$.

*Friedman repeated measures analysis of variance on ranks.

FA, fatty acids.

subsequently $5 \mathrm{ml}$ of hexane were added to the cooled tubes and shaken vigorously before centrifugation for five minutes at $600 \mathrm{~g}$. A 500 $\mu \mathrm{l}$ aliquot of the hexane phase was transferred to another tube equipped with Teflon lined screw caps. Hexane was evaporated under nitrogen. Methylation was carried out using $14 \%$ boron flouride in methanol $\left(\mathrm{BF}_{3}\right)$ according to Morrison and Smith. ${ }^{14} \mathrm{~A} 1 \mathrm{ml}$ aliquot of $\mathrm{BF}_{3}$ was added and the tightly sealed tubes were incubated in a boiling water bath for two minutes. After cooling, $2 \mathrm{ml}$ of hexane and $1 \mathrm{ml}$ of $\mathrm{H}_{2} \mathrm{O}$ were added and mixed. The hexane phase was transferred to sealed gas-liquid chromatographic vials. Fatty acid methyl esters were quantified by gas-liquid chromatography using a Hewlett Packard 5890 chromatograph with a $25 \mathrm{~m}$ fused silica capillary column $(0.32$ $\mathrm{mm}$ internal diameter, BPX70, Microlab, Aarhus, Denmark) equipped with a Hewlett Packard 5971A mass spectrometer. Peak areas were calculated by an integrator from total ion chromatograms, and concentrations of fatty acids were calculated from internal standards. The fatty acids quantified were the saturated (C8:0, C10:0, C12:0, C14:0, C16:0, C18:0, C20:0) and the unsaturated (C14:1, C16:1, C18:1, C18:2, C18:3) fatty acids and their corresponding isomers and hydroxyacids. The intestinal bacteria can convert a part of unsaturated long chain unsaturated fatty acids to the isomer and the hydroxy long chain fatty acids at the position of the double bond; for example, oleic acid, C18:1, may convert to 10-hydroxystearic acid, 10-OH-C18:0. ${ }^{15-17}$ Therefore, faecal excretions used for calculation of absorption of fatty acids were the sum of all fatty acids and their corresponding isomers and hydroxy acids. Fatty acids were identified by comparison with authentic standards and confirmed by mass spectrometry. The carrier gas was helium. Oven temperatures were $60^{\circ} \mathrm{C}$ for two minutes, followed by $4^{\circ} \mathrm{C}$ per minute until $250^{\circ} \mathrm{C}$, which was maintained for 60 minutes.
The energy conversion factors were those of Atwater et al, confirmed by Southgate and Durnin $^{18}$ : 17.6, 23.6, and $39.1 \mathrm{~kJ} / \mathrm{g}$ for carbohydrate, protein, and fat, respectively.

The fluid, energy, nitrogen, glucose, and electrolyte content of parenteral supplements was calculated from values provided by the manufacturers. The basal energy expenditure was calculated according to the HarrisBenedict equations using actual body weights. ${ }^{19}$

\section{ETHICS}

The protocol was approved by the Ethics Committee for Medical Research in Copenhagen, Denmark. All procedures were performed in accordance with the ethical standards of the Helsinki Declaration of 1975 , as revised in 1983. All patients gave informed consent.

STATISTICAL ANALYSIS

Results of the 11 patients are expressed as medians with $25 \%$ and $75 \%$ percentiles shown in brackets. Differences between ranitidine, omeprazole, and control periods were tested with the Friedman repeated measures analysis of variance on ranks using the SigmaStat for Windows Version 2.0 (Jandel Corporation, Erkrath, Germany). For all pairwise multiple comparisons, the Student-Newman-Kreuls method was used as the post hoc test. A value of $p<0.05$ was considered significant.

\section{Results}

Thirteen patients (eight women, five men), median age 46 years (25-75\% percentiles, 43-60) were studied. Two patients had 25\% and $75 \%$ of colon in continuity: one had a jejunotransverso anastomosis ending in a sigmoideostomy, the other a jejunoascendo anastomosis and no stoma. Results from these two patients are excluded from the statistical analysis and the results presented in the tables and figures. Results therefore refer to the 11 patients without a colon in continuity only- 
Table 2 Faecal excretion

\begin{tabular}{lllll}
\hline Faecal excretion & Control & Ranitidine & Omeprazole & $p$ Value* \\
\hline Weight (kg/day) & $2.93(2.33-4.36)^{\mathrm{a}}$ & $2.47(2.20-3.31)^{\mathrm{b}}$ & $2.39(2.13-2.58)^{\mathrm{c}}$ & 0.001 \\
Sodium (mmol/day) & $248(208-335)^{\mathrm{b}}$ & $230(208-335)^{\mathrm{a}}$ & $228(200-257)^{\mathrm{b}}$ & 0.04 \\
Potassium (mmol/day) & $49(34-67)$ & $43(28-50)$ & $36(29-49)$ & 0.08 \\
Calcium (mmol/day) & $37(29-46)$ & $33(28-45)$ & $33(28-47)$ & 0.70 \\
Magnesium (mmol/day) & $14(14-20)$ & $20(13-21)$ & $14(13-20)$ & 0.93 \\
Energy (MJ/day) & $5.11(4.73-6.18)$ & $4.84(4.67-5.32)$ & $5.29(4.77-6.64)$ & 0.53 \\
Nitrogen (g/day) & $9.1(8.0-10.0)$ & $8.7(7.6-9.6)$ & $9.7(7.8-12.1)$ & 0.31 \\
Carbohydrate (g/day) & $84.3(65.2-93.9)^{\mathrm{a}}$ & $77.7(55.6-85.0)^{\mathrm{a}}$ & $74.7(52.0-85.4)^{\mathrm{b}}$ & 0.02 \\
Fatty acids (g/day) & $55.2(52.3-64.2)$ & $51.7(48.0-59.8)$ & $52.2(46.1-55.1)$ & 0.06 \\
Saturated FA (g/day) & $31.8(29.5-35.2)$ & $29.8(25.1-35.4)$ & $28.3(25.8-32.9)$ & 0.15 \\
Unsaturated FA (g/day) & $24.6(21.5-28.4)$ & $23.1(21.4-26.9)$ & $22.0(18.2-25.3)$ & 0.06 \\
\hline
\end{tabular}

Values are median (25-75\%).

abc Significant difference between study periods, $\mathrm{p}<0.05$.

${ }^{\star}$ Friedman repeated measures analysis of variance on ranks.

FA, fatty acids.

that is, 10 patients with short bowel and jejunostomies and intestinal failure evidenced by a prolonged need for parenteral energy and fluids, and one with a high output ileostomy, who did not have a small bowel resection.

In these 11 patients with a jejunostomy or ileostomy the body mass index was $21.9 \mathrm{~kg} / \mathrm{m}^{2}$ (19.5-24.2). The median remnant small intestine was $125 \mathrm{~cm}$. Time since the last operation was 3.8 years $(2.5-4.7)$ and the duration of home parenteral nutrition (HPN) was 3.1 years (1.4-4.7). The median parenteral volume was 1.71 /day (1.5-4.3), parenteral sodium 151 $\mathrm{mmol} /$ day (70-360), and the parenteral energy supplement in relation to the basal energy expenditure was $64 \%$ (32-98). The body mass index in the two patients with remnant colon segments was 20.1 and $22.5 \mathrm{~kg} / \mathrm{m}^{2}$, remnant small intestines were 90 and $90 \mathrm{~cm}$, and the time since last operations and duration of HPN were 5.5 and 5.1 years, respectively. In these two patients the parenteral volumes were 2.6 and 2.4 1/day, parenteral sodium 229 and 107 $\mathrm{mmol} /$ day, and the parenteral energy supplement in relation to the basal energy expenditure 83 and $108 \%$.

The elapsed time between treatment periods was a median of 42 days (range 14-82) and the time between the last treatment period and the control period was a median of 93 days (range 11-203).

Table 1 gives the results of analysis of the diet and parenteral supplements. Median energy content of parenteral nutrition was $53 \mathrm{~kJ} / \mathrm{kg} /$ day.

Table 2 gives the results of analysis of faecal excretion. In the control period median faecal weight was $2.93 \mathrm{~kg} /$ day (range 1.74-5.66). Ranitidine and omeprazole reduced faecal weight to 2.47 and $2.39 \mathrm{~kg} /$ day, respectively, which was a median reduction of $0.42 \mathrm{~kg} /$ day (range -0.13 to 1.22 ) and $0.63 \mathrm{~kg} /$ day (range -0.31 to 2.10 ), respectively. A concurrent reduction in faecal sodium was also observed, but faecal excretion of potassium, calcium, magnesium, and energy was not changed.

Table 3 gives the results of calculation of intestinal absorption as the difference between the oral intake and faecal excretion. The weight of intestinal output exceeded the weight of diet and beverages in three patients, a phenomenon usually referred to as "secretors". ${ }^{7}$ Median wet weight absorption was $1.54 \mathrm{~kg} /$ day in the control period (range -1.36 to 4.01 ). Ranitidine resulted in a non-significant increase in wet weight absorption of a median of $0.46 \mathrm{~kg} /$ day

Table 3 Intestinal absorption

\begin{tabular}{|c|c|c|c|c|}
\hline & Control & Ranitidine & Omeprazole & $p$ Value * \\
\hline \multicolumn{5}{|l|}{ Intestinal absorption } \\
\hline Weight $(\mathrm{kg} /$ day $)$ & $1.54(0.11 \text { to } 1.93)^{\mathrm{a}}$ & $1.54(0.39 \text { to } 2.78)^{\mathrm{a}}$ & $2.01(0.82 \text { to } 2.98)^{\mathrm{b}}$ & 0.009 \\
\hline Sodium (mmol/day) & $-30(-174$ to 18$)$ & $15(-152$ to 39$)$ & $-13(-114$ to 17$)$ & 0.10 \\
\hline Potassium (mmol/day) & $42(19$ to 65$)$ & $50(30$ to 73$)$ & $38(36$ to 68$)$ & 0.76 \\
\hline Calcium ( $\mathrm{mmol} /$ day) & $-3(-20$ to 10$)$ & $5(-6$ to 9$)$ & $4(-2$ to 11$)$ & 0.44 \\
\hline Magnesium (mmol/day) & $1(-1$ to 4$)$ & $-1(-9$ to 2$)$ & $1(-1$ to 2$)$ & 0.49 \\
\hline Energy (MJ/day) & $4.72(3.06$ to 5.29$)$ & $3.94(2.55$ to 5.98$)$ & $4.11(3.41$ to 5.43$)$ & 0.53 \\
\hline Nitrogen (g/day) & $4.9(3.4$ to 8.1$)$ & $5.7(2.1$ to 6.6$)$ & $2.7(0.1$ to 5.6$)$ & 0.07 \\
\hline Carbohydrate (g/day) & 116.8 (86.1 to 163.8$)$ & $114.8(72.5$ to 160.6$)$ & $137.0(108.9$ to 186.0$)$ & 0.33 \\
\hline Fatty acids (g/day) & $17.8(5.0$ to 25.7$)$ & $13.9(-3.5$ to 25.5$)$ & $17.4(11.7$ to 30.3$)$ & 0.23 \\
\hline Saturated FA (g/day) & $9.9(3.5$ to 15.4$)$ & $7.5(-2.0$ to 15.1$)$ & $10.9(7.2$ to 17.4$)$ & 0.08 \\
\hline Unsaturated FA (g/day) & $7.4(1.4$ to 9.9$)$ & $6.5(-1.5$ to 10.4$)$ & $7.0(3.6$ to 13.1$)$ & 0.26 \\
\hline Differences in absorption & Omeprazole minus ranitidine & Ranitidine minus control & Omeprazole minus control & \\
\hline Weight (kg/day) & $0.17(0.08 \text { to } 0.74)^{\mathrm{a}}$ & $0.46(-0.11 \text { to } 0.71)^{\mathrm{a}}$ & $0.78(0.09 \text { to } 1.42)^{\mathrm{b}}$ & 0.03 \\
\hline Sodium (mmol/day) & $22(-27$ to 63$)$ & $28(-10$ to 92$)$ & $17(9$ to 75$)$ & 0.44 \\
\hline Potassium (mmol/day) & $0(-14$ to 7$)$ & $5(-6$ to 13$)$ & $4(-9$ to 8$)$ & 0.91 \\
\hline Calcium (mmol/day) & $-1(-4$ to 3$)$ & $3(-2$ to 15$)$ & $2(-3$ to 9$)$ & 0.32 \\
\hline Magnesium (mmol/day) & $0(-1$ to 1$)$ & $-1(-9$ to 1$)$ & $0(-3$ to 2$)$ & 0.74 \\
\hline Energy (MJ/day) & $0.75(-0.16$ to 1.17$)$ & $-0.36(-1.06$ to 0.59$)$ & $0.40(-1.12$ to 0.80$)$ & 0.23 \\
\hline Nitrogen (g/day) & $0.0(-4.2$ to 0.6$)$ & $-1.1(-2.4$ to 0.6$)$ & $-2.7(-4.8--1.3)$ & 0.36 \\
\hline Carbohydrate (g/day) & $24.9(-11.4$ to 60.1$)$ & $-6.5(-27.2$ to 17.3$)$ & $17.7(-9.2$ to 32.7$)$ & 0.76 \\
\hline Fatty acids (g/day) & $5.1(-4.9$ to 19.3$)$ & $0.4(-10.1$ to 15.4$)$ & $6.2(0.8$ to 19.5$)$ & 0.53 \\
\hline Saturated FA (g/day) & $4.1(-1.2$ to 11.1$)$ & $0.6(-7.4$ to 8.5$)$ & $3.1(1.2$ to 11.1$)$ & 0.44 \\
\hline Unsaturated FA (g/day) & $1.9(-2.4$ to 11.6$)$ & $1.2(-2.8$ to 6.9$)$ & $4.6(-0.2$ to 7.8$)$ & 0.61 \\
\hline
\end{tabular}

Values are median (25 to $75 \%$ )

${ }^{\mathrm{abc}}$ Significant difference between study periods, $\mathrm{p}<0.05$.

${ }^{\star}$ Friedman repeated measures analysis of variance on ranks.

FA, fatty acids. 


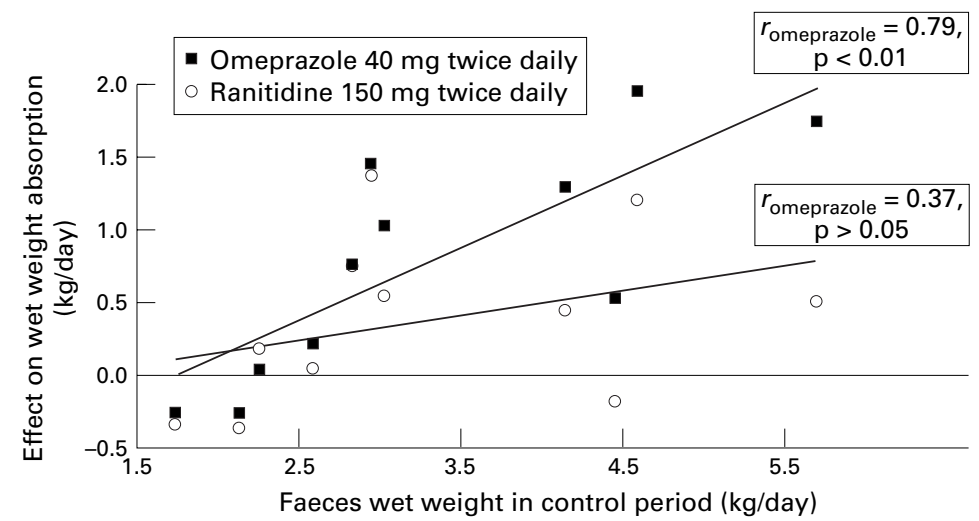

Figure 1 Effect of intravenous omeprazole and ranitidine on wet weight absorption in relation to faecal weight in the control period.

(range -0.35 to 1.37 ; fig 1 ) in comparison with the control period and intestinal absorption of sodium did not change significantly (table 3 ). Omeprazole, on the other hand, increased median absorption of wet weight by 0.78 $\mathrm{kg} /$ day (range -0.25 to 1.97 ; fig 1 ) to a total median of $2.01 \mathrm{~kg} /$ day, which was significantly more than in control and ranitidine periods (table 3 ). The absorption of sodium, potassium, calcium, magnesium, macronutrients, and total energy was similar in control, omeprazole, and ranitidine periods (table 3 ). However, when including the two patients with a remnant colon segment in the statistical analysis omeprazole also increased the absorption of sodium compared with control and ranitidine periods $\left(0 \mathrm{mmol} / \mathrm{day}^{\mathrm{a}}, 20 \mathrm{mmol} / \mathrm{day}^{\mathrm{a}}\right.$, $-4 \mathrm{mmol} /$ day $\left.^{\mathrm{b}} ; \mathrm{p}=0.02\right)$. Day to day results indicated that wet weight absorption reached steady state one day after initiation of intravenous treatment with omeprazole or ranitidine.

Figure 1 shows that the effect of omeprazole on intestinal wet weight absorption was correlated to faecal wet weight in the control period $(r=0.79, \mathrm{p}<0.01)$, in contrast to the ranitidine data $(r=0.37, \mathrm{p}>0.05)$. The effect of omeprazole was indeed negligible (median -0.10 $\mathrm{kg} /$ day) in four patients with a faecal wet weight of $2.57 \mathrm{~kg}$ /day or lower in the control period; there was however a reduction in median faecal weight of $1.30 \mathrm{~kg} /$ day in the seven patients with higher output.

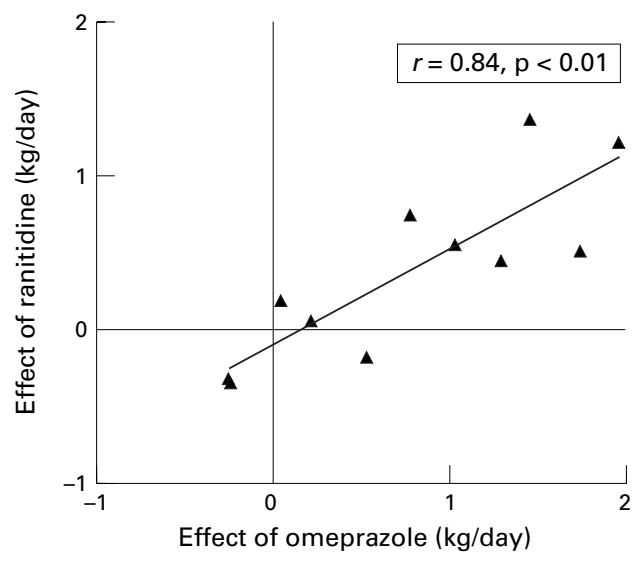

Figure 2 Correlation between the effect of intravenous omeprazole and ranitidine on wet weight absorption.
Figure 2 shows that the effect of omeprazole and ranitidine on wet weight absorption in individual patients correlated closely $(r=0.84$, $\mathrm{p}<0.01)$.

Omeprazole and ranitidine did not change urinary volume $(3.05 \mathrm{~kg} /$ day, control; 2.67 $\mathrm{kg} /$ day, ranitidine; $2.80 \mathrm{~kg} /$ day, omeprazole; $\mathrm{p}=0.49$ ), divalent cation, and nitrogen excretion, but increased urinary excretion of sodium (69 mmol/day, control; $73 \mathrm{mmol} /$ day, ranitidine; $100 \mathrm{mmol} /$ day, omeprazole; $\mathrm{p}=0.02)$ and potassium (57 mmol/day, control; $60 \mathrm{mmol} /$ day, ranitidine; $69 \mathrm{mmol} /$ day, omeprazole; $\mathrm{p}=0.01$ ).

Considering the overall balance, no significant differences were found when comparing control and study periods. The positive fluid and sodium balance of approximately 1.3 $\mathrm{kg} /$ day and $40 \mathrm{mmol} /$ day, respectively, probably accounted for losses from sweat and lung evaporation. Initial median body weights at each of the three admission periods were similar $(59.7 \mathrm{~kg}$, control; $59.3 \mathrm{~kg}$, ranitidine; 59.3 $\mathrm{kg}$, omeprazole; $\mathrm{p}=0.60)$ and stable from day to day during the study periods (ranitidine: 59.3, $57.5,59.3,62.0$, and $62.4 \mathrm{~kg} /$ day, $\mathrm{p}=0.96$; omeprazole: $59.3,58.2,59.3,62.0$, and 62.4 $\mathrm{kg} / \mathrm{day} ; \mathrm{p}=0.24$ ).

In the two patients with a remnant colon segment the dietary weight, energy, and sodium intakes in the control periods were 4.34 and $4.84 \mathrm{~kg} /$ day, 11.58 and $10.47 \mathrm{MJ} /$ day, and 217 and $252 \mathrm{mmol} /$ day, respectively. The faecal wet weight, energy, and sodium excretion were 3.30 and $2.66 \mathrm{~kg} /$ day, 7.93 and $6.02 \mathrm{MJ} /$ day, and 131 and $95 \mathrm{mmol} /$ day, respectively. Ranitidine improved the wet weight, sodium, and energy absorption by 0.29 and $0.76 \mathrm{~kg} /$ day, 23 and $129 \mathrm{mmol} /$ day, and 1.28 and $2.79 \mathrm{MJ} /$ day, in the two patients compared with the control period. Omeprazole improved the wet weight, sodium, and energy absorption by 0.61 and $1.05 \mathrm{~kg} /$ day, 69 and $142 \mathrm{mmol} / \mathrm{day}$, and 0.59 and $3.74 \mathrm{MJ} /$ day, in the two patients compared with the control period.

\section{Discussion}

This randomised, double blind, crossover study between intravenous treatment with omeprazole $40 \mathrm{mg}$ twice daily and ranitidine $150 \mathrm{mg}$ twice daily, showed that omeprazole was superior to ranitidine with regard to the effect on wet weight absorption in functional short bowel patients with a jejunostomy or ileostomy, and a faecal volume higher than $1.50 \mathrm{~kg} /$ day. If the two patients with a short bowel and remnant colon segments were included in the statistical analysis omeprazole was also superior to ranitidine with regard to the effect on sodium absorption. The effect of omeprazole was confirmed by comparison with data from an open non-randomised control period which was placed after the study periods to take into account the possible effect of intestinal adaptation with time. The improved intestinal absorption of water was not accompanied by an improved absorption of energy, fatty acids, nitrogen, or carbohydrates, and we found no effect on the intestinal absorption of electrolytes and divalent cations. Ranitidine 
increased wet weight absorption in comparison with the control period, but the differences failed to reach statistical significance, possibly due to the rather modest dose of ranitidine. Hence, the maximal dose response of the two drugs on intestinal water and sodium absorption was not evaluated in this study.

In a previously reported open study, Nightingale et al examined the effect of oral omeprazole $40 \mathrm{mg}$ once daily on intestinal output in 11 patients with short bowel and less than $150 \mathrm{~cm}$ of residual jejunum. ${ }^{7}$ Eight of the patients needed long term intravenous nutritional or fluid supplements, and seven were "secretors" compared with three in this report. Median reduction in stool wet weight was $0.43 \mathrm{~kg} /$ day and in sodium $28 \mathrm{mmol} /$ day, which was less than in our study, possibly due to the lower dose and poor bioavailability of oral omeprazole. Two secretor patients (jejunal lengths of 30 and $60 \mathrm{~cm}$ ) failed to respond to the oral administration, but responded to intravenous omeprazole or cimetidine. In the study by Nightingale et al, oral omeprazole $40 \mathrm{mg}$ did not improve intestinal energy absorption, and this is in line with our results, even in patients with an appreciable effect on sodium and water absorption.

In a placebo controlled study, Aly et al evaluated the effect of oral cimetidine $400 \mathrm{mg}$ four times daily on diarrhoea in 10 patients after the resection of 30-300 cm small bowel. ${ }^{20}$ None of the patients required parenteral supplementation. Diarrhoea was reduced by an average of $22 \%$ and faecal sodium by $27 \%$. As in our study, patients with the higher stool volumes responded better to cimetidine and faecal fat did not change.

Jacobsen et al studied the effect of increasing doses of intravenous cimetidine $200-800 \mathrm{mg}$ four times daily in eight patients from our institution on parenteral supplements with jejunostomies and median small bowels of 120 cm $(60-220 \mathrm{~cm})$ in an open study. ${ }^{8}$ Outputs were reduced with a median of $0.50 \mathrm{~kg} /$ day (0.0-2.6 kg/day) at a dose of $400 \mathrm{mg}$ four times daily. Faecal sodium was reduced by a median of $31 \mathrm{mmol} /$ day and potassium by a median of $7 \mathrm{mmol} /$ day; faecal fat did not change. These results were similar to the changes in absorption obtained in this study with an omeprazole dose of $40 \mathrm{mg}$ twice daily. Doubling the dose of cimetidine to $800 \mathrm{mg}$ four times daily showed no advantage compared with $400 \mathrm{mg}$ four times daily, and the effect of cimetidine $200 \mathrm{mg}$ four times daily was not significant in accordance with the lack of effect we found for ranitidine $150 \mathrm{mg}$ twice daily.

The mechanism by which omeprazole and ranitidine reduce faecal excretion of sodium and water is not fully established. The close correlation between the effect of omeprazole and ranitidine on wet weight absorption (fig 2) may indicate some similarity in mechanisms of action or that two mechanisms of action work in the same subgroup of patients. We are not aware of any studies which have addressed whether the combination of a $\mathrm{H}_{2}$ receptor antagonist and a proton pump inhibitor offers any further advantage, but our study indicates that patients respond to either of the drugs. Conversely, little is probably obtained by a change from one principle of action to another in patients who have failed to respond to treatment with either an $\mathrm{H}_{2}$ receptor antagonist or a proton pump inhibitor intravenously. The four patients receiving octreotide in this study had a mean faecal output of $3.96 \mathrm{~kg} /$ day. Omeprazole reduced the faecal output by $0.92 \mathrm{~g} /$ day or approximately $25 \%$ as seen in the rest of the patients. The site of action of $\mathrm{H}_{2}$ receptor antagonists and proton pump inhibitors is different from a pharmacological point of view, but it is possible that the effect of both agents on sodium and water secretion is secondary to their inhibition of gastric acid secretion and simply reflects decreased secretion of gastric juice in response to food. $\mathrm{H}_{2}$ receptors have also been found in the small intestine in animals $^{21}$ and an effect on jejunal water and electrolyte secretion is in theory a possible mechanism of action. Furthermore, both $\mathrm{H}_{2}$ receptor antagonists and proton pump inhibitors have been proposed to delay gastric emptying rates, which indirectly may improve fluid and electrolyte absorption in the small intestine. $^{22}$

As a relation between faecal weight and the effect of treatment was observed, it seems rational mainly to treat patients with large stomal outputs. Only patients with a faecal weight of more than $2.57 \mathrm{~kg} /$ day showed benefit of omeprazole $40 \mathrm{mg}$ twice daily in this study, and five of these patients had an increase in intestinal wet weight absorption of more than $1.0 \mathrm{~kg} /$ day (fig 1). Three of the patients with a jejunostomy and a patient with a remnant colon segment were convinced that the reduction in stool weight and the reduced need for parenteral saline improved the quality of life and they have consequently continued with daily intravenous infusions of omeprazole $40 \mathrm{mg}$ twice daily for $12-15$ months. However, none of the patients has been weaned from parenteral nutrition, and the increase in well being is therefore mainly related to a decrease in intestinal output rather than being less dependent on a central line. Consequently, in patients who do not give high priority to a lower stomal output, the more cost beneficial alternative is adding more saline parenterally. As medical expenses are met by the National Health Security System in Denmark, patients were not reluctant to initiate therapy with omeprazole or ranitidine due to economic considerations. If patients with the lower outputs had responded better (fig 1), this antisecretory treatment in theory might have rendered the patient independent of parenteral supplementation. The reduction obtained in intestinal loss of fluids in patients with the higher outputs was clearly too modest to have this outcome. The two patients with segments of preserved colon both had large intestinal outputs (3.30 and $2.66 \mathrm{~kg} /$ day, respectively) as evidence of poor colonic function. The two patients responded to treatment after the fashion of the rest of the patients and omeprazole reduced faecal output by 0.53 and $1.17 \mathrm{~g} /$ day, respectively. 
In conclusion, patients with functional short bowel syndrome and a high faecal output do benefit from $\mathrm{H}_{2}$ receptor antagonists and proton pump inhibitors when considering wet weight and sodium absorption. In this study intravenous omeprazole $40 \mathrm{mg}$ twice daily was superior to ranitidine $150 \mathrm{mg}$ twice daily, but based on other studies, ranitidine at a higher dose equipotent to cimitidine $400 \mathrm{mg}$ four times daily may have an antisecretory effect equal to the proton pump inhibitor. Other studies have indicated that higher doses of cimitidine are of no further benefit, whereas the maximal dose response of omeprazole on intestinal absorption of water and sodium has not been established. The parenteral route of administration of these drugs seems to offer an advantage in patients with short bowel due to unpredictable absorption of the drug. Proton pump inhibitors and $\mathrm{H}_{2}$ receptor antagonists only affect water and sodium absorption, whereas no effects on the absorption of divalent cations or macronutrients have been shown in short term studies, and these drugs will only influence the requirement of parenteral fluids and saline and do not reduce the need for parenteral supplements of energy and macronutrients. Omeprazole $40 \mathrm{mg}$ twice daily improved the median absorption of intestinal wet weight of approximately $25 \%$, and $9 / 13$ patients $(69 \%)$ responded with an increased wet weight absorption of more than 0.5 1/day, out of whom six had an increase of 1-2 $1 /$ day.

The technical assistance of Jette Christiansen, Anne Birgitte Larsen, Birthe Stenbæk Hansen, Kirsten Ahring, and AnneMarie Raabyemagle is greatly appreciated.

1 Ladefoged K. Quality of life in patients on permanent home parenteral nutrition. F Parenter Enteral Nutr 1981;5:132-7.

2 O'Hanrahan T, Irving $\mathrm{MH}$. The role of home parentera nutrition in the management of intestinal failure-report of 400 cases. Clin Nutr 1992;11:331-6.
3 Buxton B. Small bowel resection and gastric acid hypersecretion. Gut 1974;15:229-38.

4 Malagelada JR. Pathophysiological responses to meals in the Zollinger-Ellison syndrome: 2. Gastric emptying and its effect on duodenal function. Gut 1980;21:98-104.

5 Heizer WD, Cleveland CR, Iber FL. Gastric inactivation of pancreatic

Go VL, Poley JR, Hofmann AF, et al. Disturbances in fat digestion induced by acidic jejunal $\mathrm{pH}$ due to gastric hypersecretion in man. Gastroenterology 1970;58:638-46.

7 Nightingale JM, Walker ER, Farthing MJ, et al. Effect of omeprazole on intestinal output in the short bowel syndrome. Aliment Pharmacol Ther 1991;5:405-12.

8 Jacobsen O, Ladefoged K, Stage JG, et al. Effects of cimetidine on jejunostomy effluents in patients with severe shortbowel syndrome. Scand f Gastroenterol 1986;21:824-8.

9 Cortot A, Fleming CR, Malagelada JR. Improved nutrient absorption after cimetidine in short-bowel syndrome with gastric hypersecretion. N Engl f Med 1979;300:79-80.

10 Recker RR. Calcium absorption and achlorhydria. $N$ Engl f Med 1985;313:70-3.

11 Bo Linn GW, Davis GR, Buddrus DJ, et al. An evaluation of the importance of gastric acid secretion in the absorption of dietary calcium. 7 Clin Invest 1984;73:640-7.

12 AOAC. AOAC official methods of analysis. Arlington: AOAC Inc., 1984.

13 Englyst HN, Cummings JH. Non-starch polysaccharides (dietary fiber) and resistant starch. Adv Exp Med Biol 1990; 270:205-25

14 Morrison WR, Smith LM. Preparation of fatty acid methyl esters and dimethylacetals from lipids with boron fluoridemethanol. F Lipid Res 1964;5:600-8.

15 Thomas PI. Identification of some enteric bacteria which convert oleic acid to hydroxystearic acid in vitro. Gastroenterology 1972;62:430-5.

16 Soong CS, Thompson JB, Poley JR, et al. Hydroxy fatty acids in human diarrhea. Gastroenterology 1972;63:748-57.

17 Webb JPW, James AT, Kellock TD. The influence of diet on the quality of faecal fat in patients with and without steatorrhoea. Gut 1963;4:37-41.

18 Southgate DA, Durnin JV. Calorie conversion factors. An experimental reassessment of the factors used in the calculation of the energy value of human diets. Br ₹ Nutr 1970; 24:517-35.

19 Schofield WN. Predicting basal metabolic rate, new tandards and review of previous work. Hum Nutr Clin Nutr 1985;39(suppl 1):5-41.

20 Aly A, Barany F, Kollberg B, et al. Effect of an $\mathrm{H}_{2}$-receptor blocking agent on diarrhoeas after extensive small bowel resection in Crohn's disease. Acta Med Scand 1980;207: 119-22.

21 Pawlik W, Tague LL, Tepperman BL, et al. Histamine $\mathrm{H}_{1}$ and $\mathrm{H}_{2}$-receptor vasodilation of canine intestinal circulation. Am f Physiol 1977;233:E219-24.

22 Houben GM, Hooi J, Hameeteman W, et al. Twenty-fourhour intragastric acidity: $300 \mathrm{mg}$ ranitidine b.d., $20 \mathrm{mg}$ omeprazole o.m., $40 \mathrm{mg}$ omeprazole o.m. vs. placebo. Aliment Pharmacol Ther 1995;9:649-54. 